\title{
Analysing species abundance distribution patterns across sampling scales in three natural forests in Northeastern China
}

\author{
Lingzhao Tan ${ }^{(1-2)}$, \\ Peng Zhang ${ }^{(1)}$, \\ Xiuhai Zhao ${ }^{(1)}$, \\ Chunyu Fan ${ }^{(1)}$, \\ Chunyu Zhang ${ }^{(1)}$, \\ Yan Yan ${ }^{(3)}$, \\ Klaus von Gadow ${ }^{(4-5)}$
}

\begin{abstract}
Understanding how and why species abundance distributions (SADs) vary with sampling scale has been a long-standing issue in ecology. By fitting various SAD models with observations collected in three large forest field plots, the objective of this study is to explore how the shape of SADs and the predictive ability of SAD models vary with sampling scales. Based on a large dataset collected in the Changbaishan, Jiaohe and Liangshui forests in northeastern China, observed SADs were compared with SADs estimated using five different models (log-normal, broken stick, Zipf, niche preemption and neutral model) at four sampling scales $(10 \times 10 \mathrm{~m}, 30 \times 30 \mathrm{~m}, 60 \times 60 \mathrm{~m}$ and $90 \times 90 \mathrm{~m})$. The results show that the studied SADs are scale dependent. Niche-based models provided a better fit at small sample sizes, the predictive ability decreasing with increasing sampling scale. The neutral model performed better at large sample sizes, the predictive ability increasing with increasing sampling scale. We identify the models that provided the best fit to observed species abundance distributions across spatial scales, and conclude that there is not one best SAD model for all spatial scales. Future studies should consider the scale effects on the species abundance distribution.
\end{abstract}

Keywords: Community Ecology, Neutral Theory, Niche Theory, Scale Effects, Species Abundance Distribution, Temperate Forest, Woody Plants

ones (McGill et al. 2007, Matthews \& Whittaker 2014). Initially, SADs were mainly used in zoological studies (Dornelas \& Connolly 2008). Increasingly, SADs are used to describe a variety of ecological communities, including forests. Studying the species abundance distribution may explain processes of community assembly (Matthews et al. 2014), help to predict the response to disturbance (Komonen \& Elo 2017), and suggest appropriate measures of biodiversity conservation and management (Dunstan et al. 2012).

Since Motomura (1932) proposed a first SAD model in 1932, a surprising variety of models have emerged to characterize the shape of the distribution and to identify potential mechanisms resulting in a specific pattern (McGill et al. 2007). Based on specific assumptions, SAD models have been grouped into three types: (i) niche models, (ii) neutral models, and (iii) statistical models (Matthews \& Whittaker 2014). Niche models are based on niche theory which suggests that species which occupy the same niche cannot coexist with permanent stability (MacArthur 1957, Tokeshi 1993). Niche differentiation is crucial to species coexistence, but it cannot explain the extreme species richness in tropical rainforests with homogenous site conditions (Hubbell 2006). Neutral models are derived from the neutral theory which emphasizes the importance of random processes in shaping the patterns of biodiversity, such as ecological drift, immigration and speciation (Hubbell 2001, Chave 2004). Statistical models are different from the niche and neutral models in following mathematical theories more than empirical ecological processes (Fisher et al. 1943, Preston 1948). These models are often effective in the analysis of insect community structures (Williams 1964, Walker \& Cyr 2007). By fitting a model to empirical observations, the characterization of a particular model as niche-based, neutral-based or purely statistical has important implications for the in terpretation of possible driving mechanisms. Which model provides the best fit, and how the results will help to interpret the processes structuring a particular ecological system, has become an active area of research.

Sampling effects may constrain the shape of a species abundance distribution. In natural communities, species are expected to be heterogeneously distributed. The shape of the SAD is influenced by the degree to which common species dominate the individuals observed in a region, and by the total number of very rare species (McGlinn et al. 2019). It is possible that when the sampling scale changes, the abundance of common species and the number of rare species will vary with the scale. Collins \& Glenn (1997) have shown that the SADs were significantly different at each of two sampling scales among four taxonomic groups in a tall grass prairie. The percentage of core-group species declined with increasing spatial scale while the percentage of rare satellite-group species increased. Borda-De-Agua et al. (2012), using observa- 


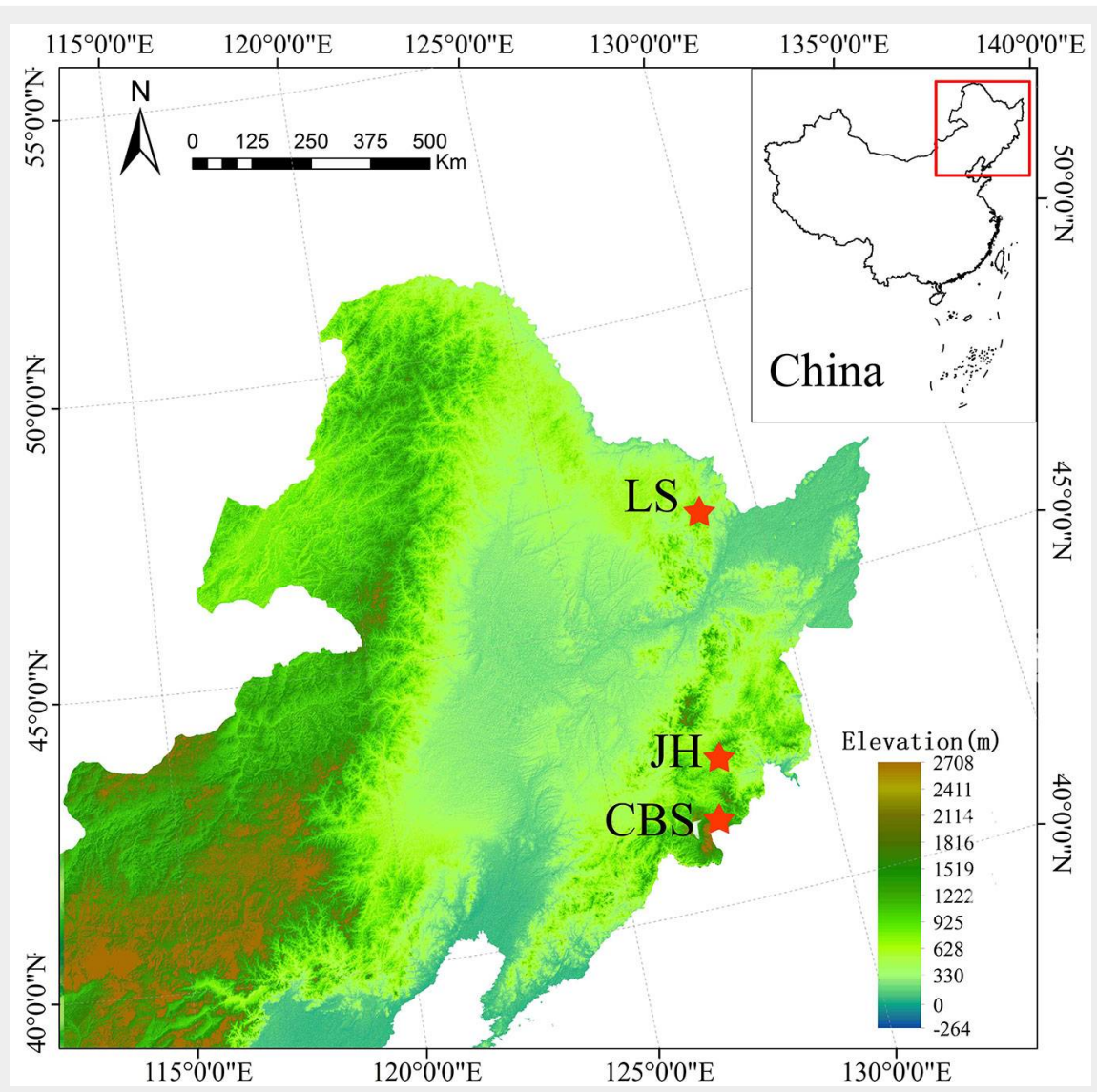

Fig. 1 - Location of the three large observational study areas in northeastern China. The Changbaishan Nature Reserve (CBS), the Jiaohe Experimental Forest (JH) and the Liangshui Nature Reserve (LS). The map was generated by ArcGIS ${ }^{\circledast}$ ver. 10.3 software (http://resources.arcgis.com/en/home/). The data is an open access DEM data obtained from the Earth Remote Sensing Data Analysis Center (https://ssl.jspacesystem s.or.jp/ersdac/GDEM/E/).

tions of tree and shrub species in a 50 ha plot of a tropical rain forest on Barro Colorado Island, found that when sampling areas increased from 1 ha to 50 ha, the SAD curves changed from monotone to unimodal. Accordingly, when SAD curves vary with spatial scales, the sampling effect makes it difficult to draw general conclusions about which model provides the best empirical fit. This finding calls for further investigation of the scale effects on $S A D$ model performance.

Supporting an abundance of plant spe cies, forests represent an important terres trial ecosystem. Compared with tropical and subtropical forests, SAD patterns have not received much attention in the temperate conifer and broad-leaved mixed forests. In this study, we examine the scale effects on SADs using observations from three large field plots located in different regions of northeastern China. Five popular models based on different ecological as sumptions were chosen, including three niche-based models (broken stick, Zipf, niche preemption), a neutral model, and a log-normal model, to simulate expected SADs. Observed SAD patterns were compared with expected patterns across four sampling scales $(10 \times 10 \mathrm{~m}, 30 \times 30 \mathrm{~m}, 60 \times$
$60 \mathrm{~m}$, and $90 \times 90 \mathrm{~m})$. The objective of this study is to examine how the shape of SADs and the predictive ability of the selected SAD models vary with varying sampling scale.

\section{Material and method}

\section{Study area}

The study was carried out in temperate conifer and broad-leaved mixed forests in Northeastern China. The last recorded harvesting activity in the study area took place more than 60 years ago. Most canopy trees are now 100-120 years old. The study area thus represents secondary forests in the middle-to-late stage of succession. The forests are influenced by a continental climate from central Asia with dry winters, and by a monsoon climate from the western Pacific that brings precipitation during summer. The average annual temperature in study area ranges between 1.1 and $3.8^{\circ} \mathrm{C}$. The annual precipitation ranges between 630 and $974 \mathrm{~mm}$. The bedrock in the study area is granite and the soils are mostly brown forest soils with a rootable depth ranging between 10 and $130 \mathrm{~cm}$. Major tree species in the study area include deciduous broad-leaved species such as Tilia amuren- sis, Quercus mongolica, Betula ermanii, Populus ussuriensis and Fraxinus mandschurica. The dominant conifer species are Pinus koraiensis, Abies fabri, and Picea jezoensis. Dominant shrub species are Acanthopanax senticosus, Corylus mandshurica, Syringa reticulata, and Philadelphus schrenkii.

\section{Sampling design}

Three large field plots were established in the Changbaishan Nature Reserve (CBS), the Jiaohe Experimental Forest $(\mathrm{JH})$ and the Liangshui Nature Reserve (LS - Fig. 1). The CBS plot is located at $42^{\circ} 04^{\prime}-42^{\circ} 23^{\prime} \mathrm{N}$ and $127^{\circ} 55^{\prime}-128^{\circ} 08^{\prime} \mathrm{E}$. This plot was established in 2014 covering an area of 40 ha $(500 \times 800 \mathrm{~m})$. The elevation in CBS ranges from 991 to $1046 \mathrm{~m}$. The topography is almost flat, slopes are less than five degrees. The $\mathrm{JH}$ plot is located at $43^{\circ} 57^{\prime}-43^{\circ} 58^{\prime} \mathrm{N}$, $127^{\circ} 44^{\prime}-127^{\circ} 45^{\prime} \mathrm{E}$. The plot was established in 2010 and remeasured in 2015 covering an area of 30 ha $(500 \times 600 \mathrm{~m})$. The topographic variation is considerable with elevations ranging from 578 to $781 \mathrm{~m}$ a.s.l., and a gully between two slopes (facing southeast and southwest). The LS plot is located at $47^{\circ} 07^{\prime}-47^{\circ} 14^{\prime} \mathrm{N}, 128^{\circ} 48^{\prime}-128^{\circ}$ $55^{\prime} \mathrm{E}$. The plot was established in 2010 and remeasured in 2015 covering an area of 29.64 ha $(380 \times 780 \mathrm{~m})$. The topography of the plot is flat with elevations ranging from 380 to $400 \mathrm{~m}$ a.s.l.

All woody plants with a diameter at breast height $(d b h) \geq 1 \mathrm{~cm}$ were tagged, measured and identified to species. The coordinates of all woody-plant individuals were mapped to the nearest decimeter by steel tape. Altogether 109,338 individual stems were recorded in CBS, 44,583 in $\mathrm{JH}$ and 27,879 in the LS plot, belonging to 43 , 48 and 32 species, respectively.

\section{Data processing}

The CBS data of 2014 and the JH and LS data of 2015 were used in this study. To as sess the scale effect on species abundance patterns, we considered four sampling unit sizes, namely $10 \times 10 \mathrm{~m}$ (0.01 ha), $30 \times 30 \mathrm{~m}$ (o.09 ha), $60 \times 60 \mathrm{~m}$ ( $0.36 \mathrm{ha}$ ) and $90 \times 90$ $\mathrm{m}$ (0.81 ha). This particular range of sampling unit size is widely used in studies on forest communities aimed at detecting environmental change of soil and topographical properties as well as spatial aggregation within a local community (De Cáceres et al. 2012, Fan et al. 2017, Tan et al. 2017). For the calculations at each sampling scale, we divided the area of each plot into a grid of cells. The species abundance was calculated for each cell. The observed species abundances are represented as the mean values of all cells. Tab. 1 shows the number of cells, the total area, the number of sampled individuals. Tab. 2 presents the variability of species richness, abundance and evenness for each sampling design.

Five SAD models that have been widely used in the ecological literature were selected for modeling. Most importantly, these models are all based on specific eco- 
logical assumptions which may help to understand certain assembly processes of forest communities. The broken stick (MacArthur 1957), niche-preemption (Motomura 1932) and Zipf (Frontier 1985) models are niche based, while the neutral model (Hubbell 2001) is based on neutral theory. The lognormal model (Preston 1948) was originally thought to be purely statistical resulting from the central limit theorem (May 1975). It has been shown, however, to be also associated with niche preemption and population dynamics (Engen \& Lande 1996, Etienne \& Olff 2005). More details about the five models are present in Appendix 1 (Supplementary material).

The chi-square $\left(X^{2}\right)$ statistic at $95 \%$ confidence level was used to test the discrepancy of the expected and observed SAD patterns. We used the Bayesian Information Criterion (BIC) to compare the models
Tab. 1 - General information about the three observational field studies and sampling design used in this analysis.

\begin{tabular}{|c|c|c|c|c|c|}
\hline Plot & $\begin{array}{l}\text { Sampling } \\
\text { scale } \\
(\mathrm{m} \times \mathrm{m})\end{array}$ & $\begin{array}{l}\text { No. of } \\
\text { sampling } \\
\text { plots }\end{array}$ & $\begin{array}{l}\text { Total } \\
\text { area } \\
\text { (ha) }\end{array}$ & $\begin{array}{c}\text { No. of } \\
\text { individuals }\end{array}$ & $\begin{array}{l}\text { No. of } \\
\text { species }\end{array}$ \\
\hline \multirow{4}{*}{ CBS } & $10 \times 10$ & 4,000 & 40.00 & 109,338 & \multirow{4}{*}{43} \\
\hline & $30 \times 30$ & 416 & 37.44 & 102,964 & \\
\hline & $60 \times 60$ & 104 & 37.44 & 102,964 & \\
\hline & $90 \times 90$ & 40 & 32.40 & 90,208 & \\
\hline \multirow{4}{*}{$\mathrm{JH}$} & $10 \times 10$ & 3,000 & 30.00 & 44,583 & \multirow{4}{*}{48} \\
\hline & $30 \times 30$ & 320 & 28.80 & 43,443 & \\
\hline & $60 \times 60$ & 80 & 28.80 & 43,443 & \\
\hline & $90 \times 90$ & 30 & 24.30 & 36,873 & \\
\hline \multirow{4}{*}{ LS } & $10 \times 10$ & 2,964 & 29.64 & 27,879 & \multirow{4}{*}{32} \\
\hline & $30 \times 30$ & 312 & 28.08 & 26,185 & \\
\hline & $60 \times 60$ & 78 & 28.08 & 26,185 & \\
\hline & $90 \times 90$ & 32 & 25.92 & 24,674 & \\
\hline
\end{tabular}

Tab. 2 - The variability of species richness, abundance and evenness for each sampling design. (SD): standard deviation.

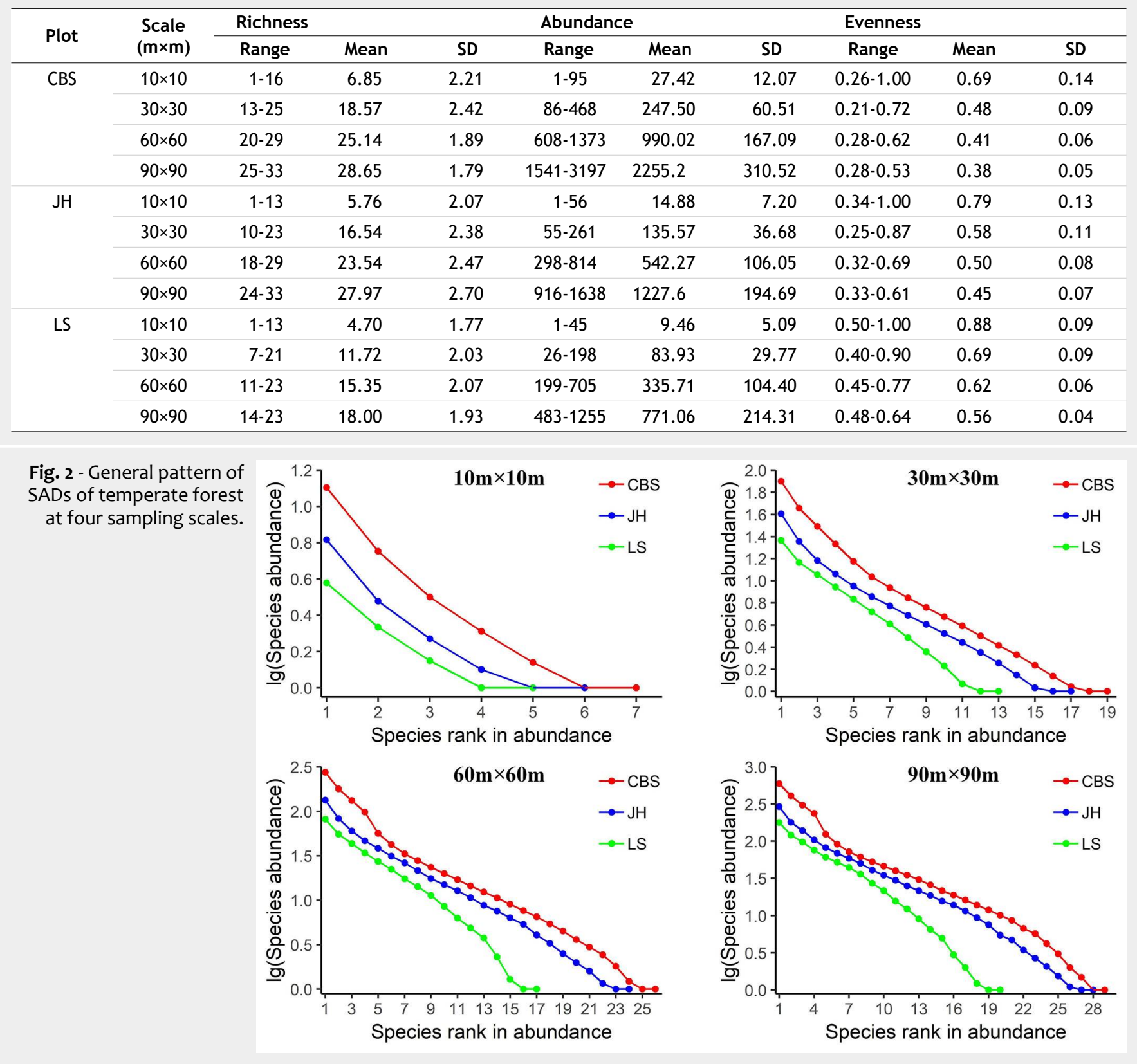



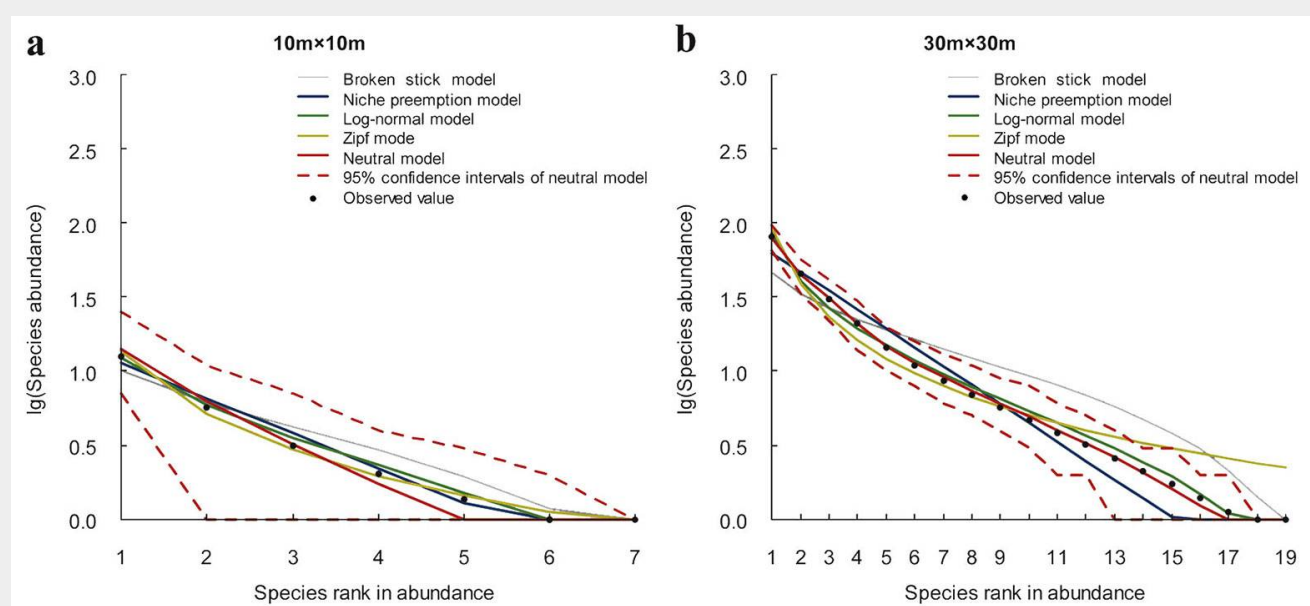

Fig. 3 - Observed and modeled SADs at four sampling scales at the Changbaishan study area.

c $60 \mathrm{~m} \times 60 \mathrm{~m}$
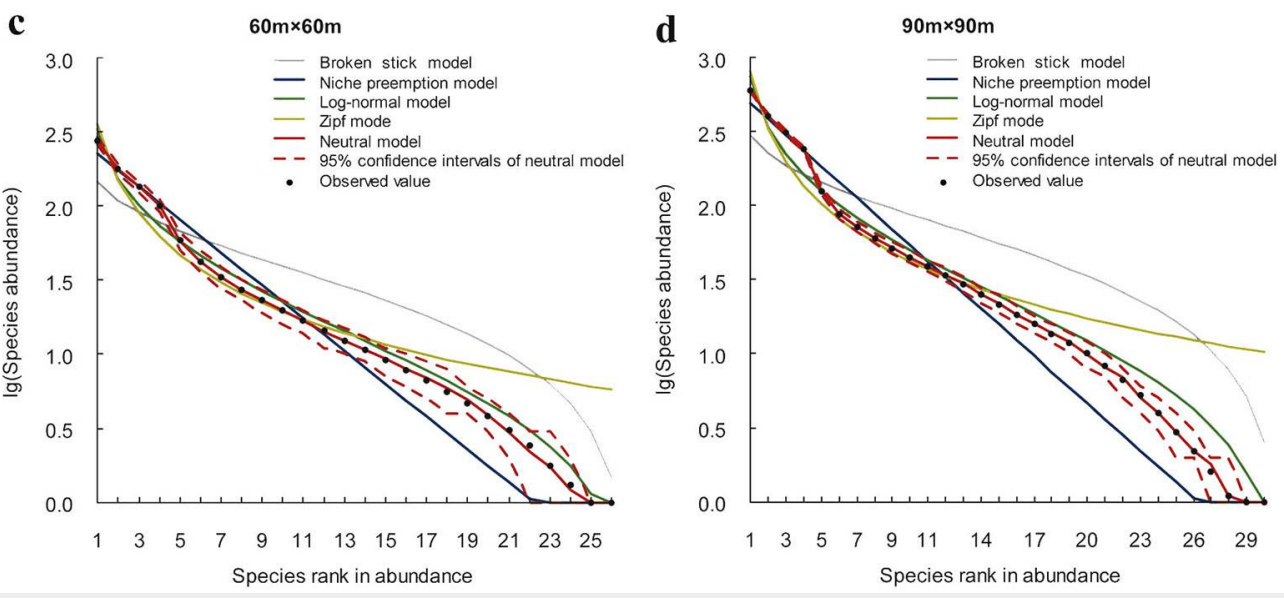

and to identify the optimum one with the lowest $\mathrm{BIC}$ value.

All calculations were carried out in $\mathrm{R}$ ver. 3.2.3 (R Development Core Team 2016) using the package "vegan" (Oksanen et al. 2009) and the package "untb" (Hankin 2007). The R script that was used to generate the major results is presented in Appendix 2 (Supplementary material).

\section{Results}

In this study, data of three plots in temperate conifer and broad-leaved mixed forests were analyzed, to check if the sampling effects on SAD pattern are consistent across all localities. For each sampling scale, (i) the general pattern of the SAD (Fig. 2), (ii) the expected SADs for the five candidate models (Fig. 3, Fig. 4, Fig. 5), and (iii) the predictive ability of each SAD model (Tab. 3) are presented. As shown in Fig. 2, the SAD patterns are similar in the three localities, but vary substantially with sample scale. SADs of the smallest sampling scale $(10 \times 10 \mathrm{~m})$ are characterized by low species richness and high unevenness, with a few common species and some rare species, and a steep decline in the ranked species abundance. As the sample size increases, species richness and evenness are increasing, as well as the number of rare species. The rate of decrease in the ranked species abundance is decreasing. The SADs of the large scales are characterized by high species richness and evenness, with some common species and a large proportion of rare species.

The predictive ability of the SAD models varies significantly with the sampling scale. The results of chi-square tests and BIC comparison show that, at small sample sizes $(10 \times 10 \mathrm{~m}$ and $30 \times 30 \mathrm{~m})$ almost all models show a good fit (Fig. 3, Fig. 4, Fig. 5 , Tab. 3). LNM or BSM show the best performance. The observed species abundance distributions thus meet the ecological assumption in all candidate models, but the statistical and niche based models perform better than the neutral model. As sample size increases, more models are rejected since the expected SADs are significantly different from the observed SADs. For example, at the $60 \times 60 \mathrm{~m}$ scale, the rejected models include BSM, ZM and NPM for Changbaishan, BSM and ZM for Jiaohe, ZM for Linagshui. At the $90 \times 90 \mathrm{~m}$ scale, the rejected models include BSM, ZM, NPM and LNM for Changbaishan, and BSM, ZM and LNM for both Jiaohe and Liangshui. The rejected models are mostly nichebased, and the number of rejections is increasing with increasing sampling sizes, indicating that the predictive ability of niche models decrease with increasing sampling scale. The results also show that NM is the best model at large sampling sizes $(60 \times 60$ $\mathrm{m}$ and $90 \times 90 \mathrm{~m}$ ) in all three localities, indicating that the species abundance distributions can be better explained by the neutral assumption, and the predictive ability of neutral model is increasing with sampling scale.

\section{Discussion}

SAD curves change with sample size because the detected diversity patterns are affected by sampling. Species richness increased by about $76 \%, 79 \%$ and $74 \%$ towards the largest grain sizes respectively in Changhaishan, Jiaohe and Liangshui. while abundance increased by about $99 \%$ in all three localities. Evenness decreased by about $64 \%, 46 \%$ and $56 \%$ with increasing grain size, respectively (Tab. 2). The rare species (13, 18 and 11 rare species in Changbaishan, Jiaohe and Liangshui, respectively), mainly includes big canopy trees and small shrubs, such as Deutzia parviflora, Tilia mandshurica, Rosa davurica, Populus davidiana in Changbaishan; Sambucus williamsii, Salix koreensis, Lonicera ruprechtiana, Acer triflorum in Jiaohe; Populus nigra, Rhamnus diamantiaca, Maackia amurensis, Juglans mandshurica in Liangshui, are more likely to be detected in large samples (Magurran 2004), which may cause the shape of SAD in rank-abundance plot to become less steep (McGill et al. 2007). Bazzaz (1975) found a similar result when the temporal scale changed as more species are added with progressive succession. McGill et al. (2007) found that the SAD curve of species-poor boreal forests is rather flat which could be represented by a geometric model; in contrast, the extreme species- 
Fig. 4 - Observed and modeled SADs at four sampling scales at the Jiaohe study area.

$\mathbf{a}$

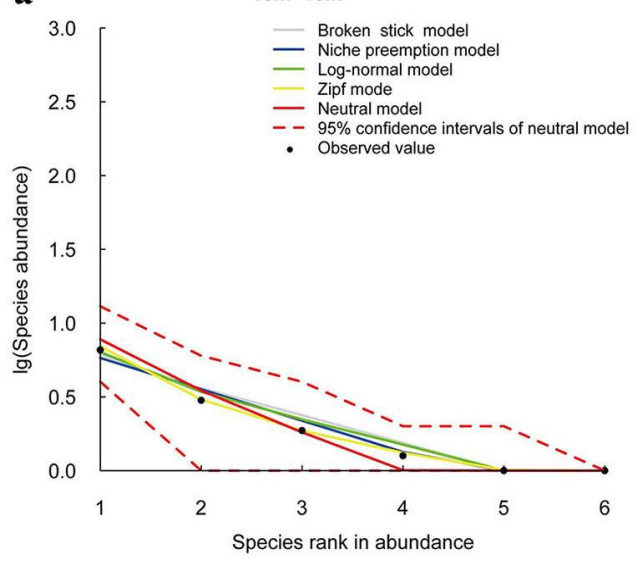

c

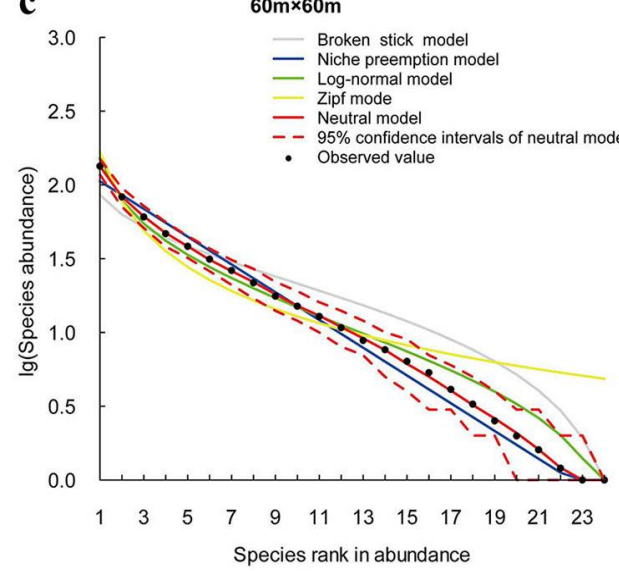

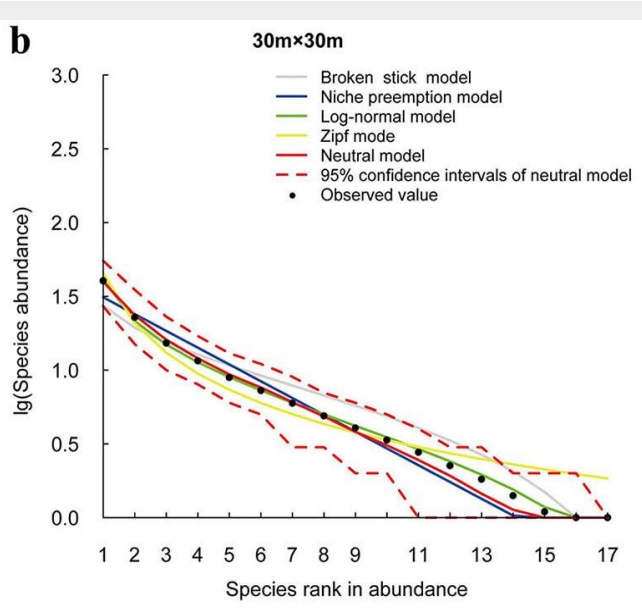

d

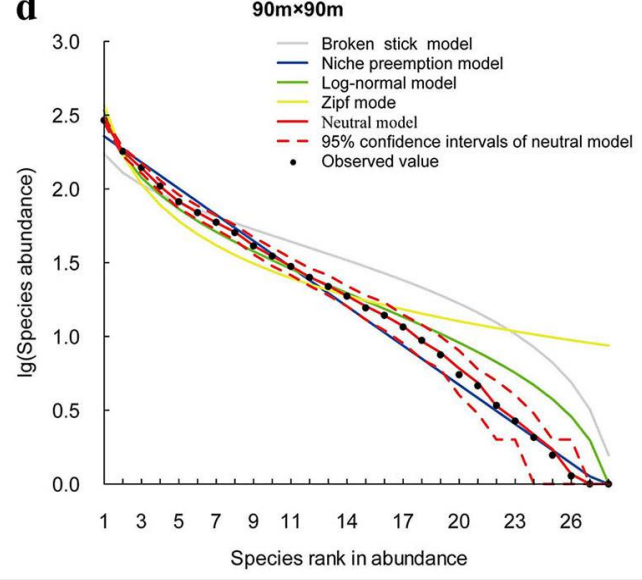

Fig. 5 - Observed and modeled SADs at four sampling scales at the Liangshui study area.

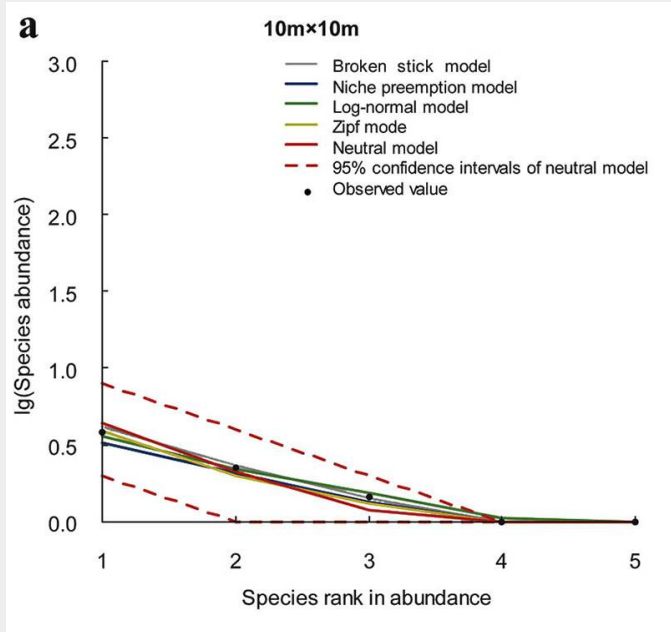

c

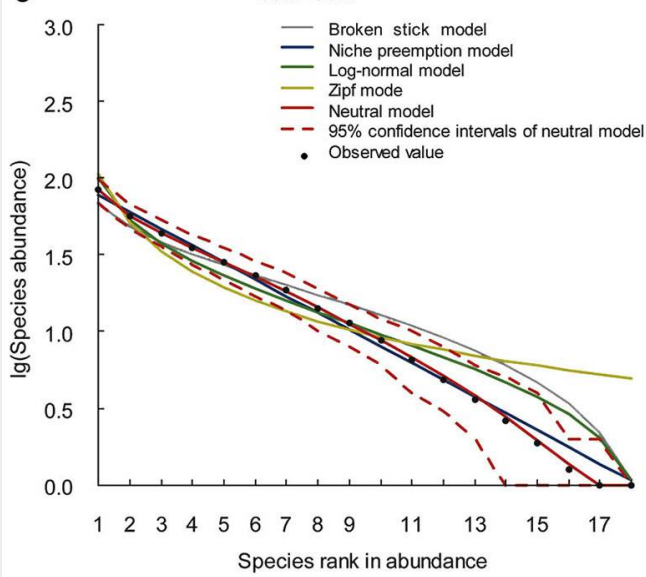

\section{b $30 \mathrm{~m} \times 30 \mathrm{~m}$}
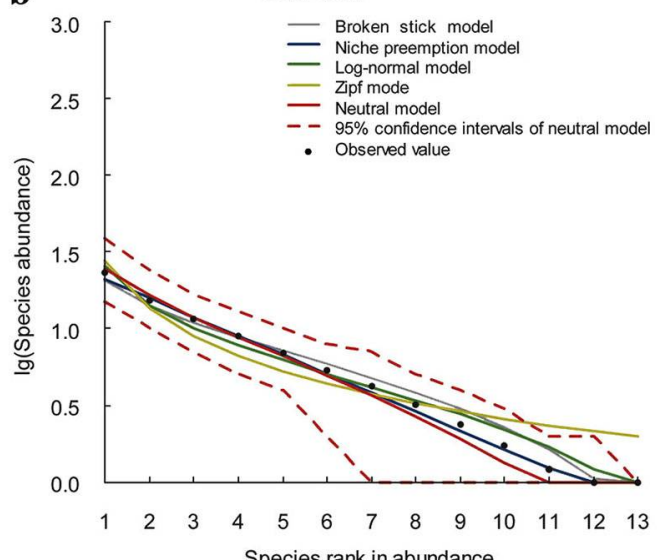

d

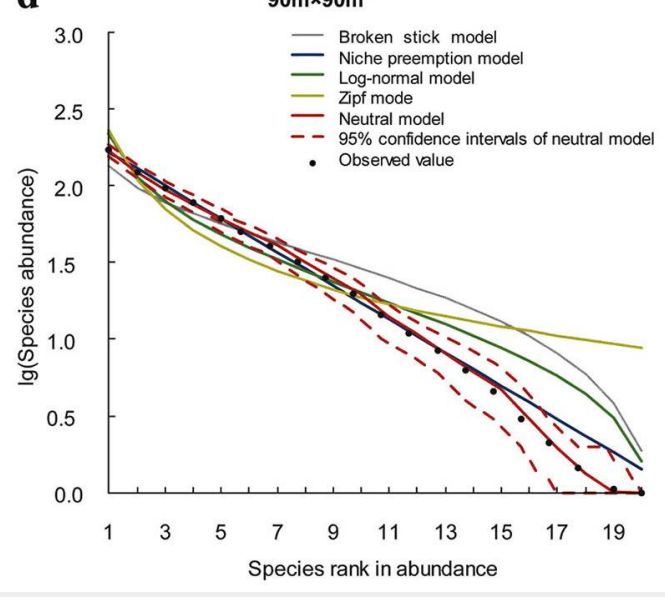


Tab. 3 - Goodness-of-fit test of five models and parameters of the neutral model at four sampling scales. $\theta$ is the fundamental diversity index, a parameter of the neutral theory model; $m$ is the immigration rate, a parameter of the neutral theory model. The models were tested at the $95 \%$ confidence level, the significant different model were rejected by the test. $\left({ }^{* *}\right): p<0.01 ;\left({ }^{*}\right): 0.01<p<0.05$. (NM): neutral model; (BSM): broken stick model; (NPM): niche preemption model; (LNM): log-normal model; (ZM): Zipf model. CBS, JH and LS refer to Changbaishan, Jiaohe and Liangshui, respectively. (BIC): Bayesian Information Criterion.

\begin{tabular}{|c|c|c|c|c|c|c|c|c|c|}
\hline Plot & $\begin{array}{l}\text { Sampling } \\
\text { scale }(m)\end{array}$ & $\begin{array}{l}\text { Testing } \\
\text { method }\end{array}$ & LNM & BSM & ZM & NPM & NM & $\theta$ & $m$ \\
\hline \multirow[t]{8}{*}{ CBS } & \multirow[t]{2}{*}{$10 \times 10$} & $\mathrm{BIC}$ & -4.71 & 0.90 & -1.95 & -0.53 & 1.37 & 2.73 & $5.1 \cdot 10^{-2}$ \\
\hline & & $\chi^{2}$ & 0.17 & 1.64 & 0.24 & 0.56 & 0.97 & & \\
\hline & \multirow[t]{2}{*}{$30 \times 30$} & $\mathrm{BIC}$ & 19.14 & 38.84 & 30.48 & 29.26 & -13.56 & 4.63 & $9.4 \cdot 10^{-3}$ \\
\hline & & $\chi^{2}$ & 2.81 & $60.23^{*}$ & 20.35 & 10.29 & 0.30 & & \\
\hline & \multirow[t]{2}{*}{$60 \times 60$} & $\mathrm{BIC}$ & 67.78 & 82.25 & 76.06 & 62.80 & -30.80 & 4.77 & $2.4 \cdot 10^{-3}$ \\
\hline & & $\chi^{2}$ & 34.13 & $430.76^{* *}$ & $200.20^{* *}$ & $51.67^{* *}$ & 0.15 & & \\
\hline & \multirow[t]{2}{*}{$90 \times 90$} & $\mathrm{BIC}$ & 104.14 & 119.55 & 112.35 & 96.61 & -29.37 & 4.98 & $1.1 \cdot 10^{-3}$ \\
\hline & & $\chi^{2}$ & $114.21^{* *}$ & $1385.00^{* *}$ & $809.68^{* *}$ & $174.57^{* *}$ & 0.54 & & \\
\hline \multirow[t]{8}{*}{$\mathrm{JH}$} & \multirow[t]{2}{*}{$10 \times 10$} & $\mathrm{BIC}$ & -3.55 & -5.42 & -5.12 & -3.27 & 0.46 & 3.20 & $1.1 \cdot 10^{-1}$ \\
\hline & & $\chi^{2}$ & 0.14 & 0.34 & 0.08 & 0.27 & 0.61 & & \\
\hline & \multirow[t]{2}{*}{$30 \times 30$} & $\mathrm{BIC}$ & -6.69 & 20.83 & 14.57 & 18.19 & -6.38 & 4.93 & $1.8 \cdot 10^{-2}$ \\
\hline & & $\chi^{2}$ & 0.22 & 10.36 & 8.39 & 4.76 & 0.67 & & \\
\hline & \multirow[t]{2}{*}{$60 \times 60$} & $\mathrm{BIC}$ & 38.35 & 54.64 & 52.26 & 44.43 & -23.53 & 4.99 & $4.6 \cdot 10^{-3}$ \\
\hline & & $\chi^{2}$ & 10.28 & $86.70^{* *}$ & $124.92^{* *}$ & 12.13 & 0.12 & & \\
\hline & \multirow[t]{2}{*}{$90 \times 90$} & $\mathrm{BIC}$ & 66.12 & 84.21 & 79.96 & 69.82 & -20.11 & 5.00 & $2.0 \cdot 10^{-3}$ \\
\hline & & $\chi^{2}$ & $41.94^{*}$ & $336.02^{* *}$ & $466.16^{* *}$ & 31.18 & 0.20 & & \\
\hline \multirow[t]{8}{*}{ LS } & \multirow[t]{2}{*}{$10 \times 10$} & $\mathrm{BIC}$ & -18.03 & -17.78 & -16.16 & -12.12 & -8.74 & 3.83 & $2.1 \cdot 10^{-1}$ \\
\hline & & $\chi^{2}$ & 0.03 & 0.17 & 0.09 & 0.01 & 0.28 & & \\
\hline & \multirow[t]{2}{*}{$30 \times 30$} & $\mathrm{BIC}$ & 1.05 & -4.27 & 13.03 & -0.46 & -1.00 & 3.62 & $2.2 \cdot 10^{-2}$ \\
\hline & & $\chi^{2}$ & 0.71 & 0.47 & 6.89 & 0.39 & 0.91 & & \\
\hline & \multirow[t]{2}{*}{$60 \times 60$} & $\mathrm{BIC}$ & 29.28 & 24.94 & 36.27 & 13.60 & -13.93 & 3.64 & $5.4 \cdot 10^{-3}$ \\
\hline & & $\chi^{2}$ & 14.29 & 23.05 & $93.49^{* *}$ & 2.44 & 0.08 & & \\
\hline & \multirow[t]{2}{*}{$90 \times 90$} & $\mathrm{BIC}$ & 52.33 & 50.33 & 59.21 & 31.25 & -13.63 & 3.86 & $2.5 \cdot 10^{-3}$ \\
\hline & & $\chi^{2}$ & $72.16^{* *}$ & $189.41^{* *}$ & $447.82^{* *}$ & 8.99 & 0.31 & & \\
\hline
\end{tabular}

rich tropical forests usually produce SAD curves that follow the neutral model.

In our study, the predictive ability of the niche models decreased with increasing sampling scale, for a series of possible reasons. From a statistical perspective, when the total area of the study plot is fixed, the number of samples at a small grain is greater than that of a large grain. The level of uncertainty associated with parameter estimates increases with decreasing number of samples, i.e., with increasing size of the individual sampling units. When the number of samples is small, outliers carry more weight than if more data are available to buffer their effects (Wisz et al. 2008). From the ecological perspective, the attributes of an ecological niche is highly dimensional, and the species response to the environment may be skewed or multimodal (Austin 2002). At small sampling grains, the environment is more homogenous in each sample, and the diversity pattern is mainly dominated by inter-species competition. This may corroborate the niche preemption hypothesis (Bazzaz 1975), which implies that one dominant species may occupy a large fraction of the total niche space, while a second species occupies a similar fraction of the remaining niche space (Motomura 1932). With increasing size of sampling units, more heterogeneous environments are included, and the interaction between species and environment becomes more complicated. Such effects may not be well represented by a single-process-based niche model.

The predictive ability of the neutral model increased with increasing sampling scale. The neutral theory predicts that the shape of the local species abundance distribution is a function of the immigration rate (Green \& Plotkin 2007). The immigration rate is likely to be associated with regeneration of new individuals of additional species. In our study, the observed communities are stable with hardly any immigration of new species. Most species in our communities regenerate by seed. As a consequence, the decreasing immigration rate $(m)$ associated with increasing sampling scale, indicates that the spatial turnover of species is greater at small sample unit sizes, and that the intraspecific aggregation is greater at large sample unit sizes. This observation may reflect an increasing effect of a spe- cies dispersal limitation (Foster \& Warton 2007) which suggests that the dispersal mode in our temperate forests (where most broad-leaved trees disperse seeds by wind, conifer trees and shrubs by gravity and animals), may be a key factor in shaping the community pattern at large scales. This observation is consistent with the results of Wang et al. (2008), who found that in temperate forests in northeastern China, the distribution of trees and shrubs are aggregated because species richness and abundance do not change with sample size in an unbiased way. They concluded that the spatial heterogeneity may be the result of within-community disturbances such as windthrow, fire and insects, which promote the regeneration of a diverse array of species. Green \& Plotkin (2007) also found that the observed left-skewness at larger scales could have resulted from increasing dispersal limitation.

Our findings differ from previous studies which reported that neutral processes are often thought to dominate in species-rich tropical forests. However, in our temperate forests, the number of species found ( 32 to 48 on 20 to 40 ha - Tab. 1) is more limited, and neutral models show nevertheless a good fit at almost all scales. It is possible that this unexpected result originates from over-fitting of the neutral models. The format of the neutral model possesses the ability to fit many observed patterns with smooth curves. In some situations, the better fit of a neutral model may be the result of a greater flexibility compared to other models without necessarily implying a dominance of neutral processes. We assume that the neutral model which showed better performance at large sampling scales, may reveal underlying processes, such as the aforementioned dispersal limitation, that generated a particular pattern. Foster \& Warton (2007) found that the better fit of a neutral model may indicate particular plant communities at similar environmental conditions are composed of neutrally-interacting species.

When comparing the relative accuracy of different models across sampling scales, we found that model performance depends on the scale. Niche-based models gave a better fit at small scales while the neutral model performed better at large scales. This result is consistent with Gao et al. (2018) who reported that, in temperate forests, dominance of species with positive effects on diversity at small scales (0-10 m) supports niche theory, that species diversity is improved by variation in niche utilization. Dominance of neutral species, i.e., species with no significant effects on diversity, at large scales (10-50 m) supported the assumption that community diversity was a result of a neutral process. These findings suggest that both niche and neutral processes are important in structuring a community. Actually, the connection between neutral or niche distribution is not completely exclusive (Etienne \& Olff 2005). For 
example, broken stick model (MacArthur 1957 ) is usually interpreted as niche-based when viewed as a sequential breakage model, but may just as well be regarded as neutral when viewed as a stochastic simultaneous breakage model (Tokeshi 1990, 1993). Such results imply that interpretations based on a single pattern should be interpreted with caution. To accurately predict SAD's of similar ecosystems, observations in large plots and across sampling scales are required.

\section{Conclusions}

Based on observations from three large field plots with mapped trees in the temperate forests in northeastern China, five different SAD models were used to examine how expected SADs differ from observed ones across four sampling scales. The results show strong effects of sampling scales on SAD. The primary results are: (i) the shape of the species abundance distribution varies with the sampling scale; (ii) the predictive ability of the niche-based model decreased with increasing sampling scale; (iii) the predictive ability of the neutral model increased with increasing sampling scale; (iv) the niche-based models provided a better fit at the small sampling scales, while the neutral model gave a better fit at the large sampling scales. The fact that only three (though very large) localities were included limits the general validity of our findings. We conclude that there is no inherently superior model representing the SADs, and recommend that in future studies the scale effects in SAD modeling should be given greater attention.

\section{Acknowledgements}

This research is supported by the Key Project of National Key Research and Development Plan (2017YFC0504005) and the Program of National Natural Science Foundation of China (31670643). This paper has benefitted from the valuable suggestions of two anonymous reviewers.

\section{References}

Austin MP (2002). Spatial prediction of species distribution: an interface between ecological theory and statistical modelling. Ecological Modelling 157 (2-3): 101-118. - doi: 10.1016/S03043800(02)00205-3

Bazzaz FA (1975). Plant species diversity in oldfield successional ecosystems in southern IIlinois. Ecology 56 (2): 485-488. - doi: 10.2307/19 34981

Borda-De-Agua L, Borges PAV, Hubbell SP, Pereira HM (2012). Spatial scaling of species abundance distributions. Ecography 35: 549-556. doi: 10.1111/j.1600-0587.2011.07128.x

Chave J (2004). Neutral theory and community ecology. Ecology Letters 7: 241-253. - doi: 10.1111/j.1461-0248.2003.00566.x

Collins SL, Glenn SM (1997). Effects of organismal and distance scaling on analysis of species distribution and abundance. Ecological applications 7: 543-551. - doi: 10.1890/1051-0761(1997) 007[0543:EOOADS]2.0.CO;2
De Cáceres $M$, Legendre $P$, Valencia $R$, Cao $M$, Chang LW, Chuyong G, Condit R, Hao Z, Hsieh $C F$, Hubbell $S$, Kenfack $D, M a K, M i X$, Noor MNS, Kassim AR, Ren H, Su SH, Sun IF, Thomas $D$, Ye W, He F (2012). The variation of tree beta diversity across a global network of forest plots. Global Ecology and Biogeography 21 (11): 1191-1202. - doi: 10.1111/j.1466-8238.2012.00770.x Dornelas M, Connolly SR (2008). Multiple modes in a coral species abundance distribution. Ecology Letters 11 (10): 1008-1016. - doi: 10.1111/j.146 1-0248.2008.01208.x

Dunstan PK, Bax NJ, Foster SD, Williams A, Althaus $F$ (2012). Identifying hotspots for biodiversity management using rank-abundance distribution. Diversity and Distributions 18: 22-32. doi: 10.1111/j.1472-4642.2011.00838.x

Etienne RS, Olff H (2005). Confronting different models of community structure to speciesabundance data: a bayesian model comparison. Ecology Letters 8 (5): 493-504. - doi: 10.1111/j. 1461-0248.2005.00745.x

Engen S, Lande R (1996). Population dynamic models generating species abundance distributions of the gamma type. Journal of Theoretical Biology 178 (3): 325-331. - doi: 10.1006/jtbi.1996. 0028

Fan C, Tan L, Zhang C, Zhao X, Gadow KV (2017). Analysing taxonomic structures and local ecological processes in temperate forests in north eastern china. BMC Ecology 17 (1): 10854. - doi: 10.1186/s12898-017-0143-y

Fisher RA, Cobert AS, Williams CB (1943). The relation between the number of species and the number of individuals in a random sample of an animal population. Journal of Animal Ecology 12: 42-58. - doi: 10.2307/1411

Foster MA, Warton DI (2007). A metacommunity-scale comparison of species-abundance distribution models for plant communities of Eastern Australia. Ecography 30 (4): 449-458. doi: 10.1111/j.0906-7590.2007.04899.x

Frontier S (1985). Diversity and structure in aquatic ecosystems. Oceanography and Marine Biology 23: 253-312.

Gao J, Zhang P, Zhang X, Liu Y (2018). Multi-scale analysis on species diversity within a 40-ha oldgrowth temperate forest. Plant Diversity 40 (2): 45-49. - doi: 10.1016/j.pld.2017.12.003

Green JL, Plotkin JB (2007). A statistical theory for sampling species abundances. Ecology Letters 10 (11): 1037-1045. - doi: 10.1111/j.1461-0248. 2007.01101.x

Hankin RKS (2007). Introducing untb, an R package for simulating ecological drift under the unified neutral theory of biodiversity. Journal of Statistical Software 22 (12): 1-15. [online] URL: http://www.jstatsoft.org/article/view/v022 i12

Hubbell SP (2001). The unified neutral theory of biodiversity and biogeography. Princeton University Press, Princeton, NJ, USA, pp. 375. [online] URL: http://books.google.com/books?id= EIQpFBu84NoC

Hubbell SP (2006). Neutral theory and the evolution of ecological equivalence. Ecology 87 : 1387-1398. - doi: 10.1890/0012-9658(2006)87[13 87:NTATEO]2.0.CO;2

Komonen A, Elo M (2017). Ecological response hides behind the species abundance distribution: community response to low-intensity dis- turbance in managed grasslands. Ecology and Evolution 7 (20): 8558-8566. - doi: 10.1002/ece3. 3395

MacArthur RH (1957). On the relative abundance of bird species. Proceedings of the National Academy of Sciences USA 43: 293-295. - doi: 10.1073/pnas.43.3.293

McGlinn DJ, Xiao X, May F, Daniel McGlinn J X, Xiao Felix May Gotelli NJ, Engel T, Blowes SA, Knight TM, Purschke O, Chase JM, McGill BJ (2019). Measurement of Biodiversity (MoB): a method to separate the scale-dependent effects of species abundance distribution, density, and aggregation on diversity change. Methods in Ecology and Evolution 10: 258-269. doi: $10.1111 / 2041-210 X .13102$

Magurran AE (2004). Measuring biological diversity. Blackwell Science, Oxford, UK, pp. 264. [online] URL: http://books.google.com/books? id=fljsaxmL_S8C

Matthews TJ, Whittaker RJ (2014). Fitting and comparing competing models of the species abundance distribution: assessment and prospect. Frontiers of Biogeography 6 (2): 67-82. doi: $10.21425 / F_{5} 6220607$

Matthews TJ, Borges PAV, Whittaker RJ (2014). Multimodal species abundance distributions: a deconstruction approach reveals the processes behind the pattern. Oikos 123: 533-544. - doi: 10.1111/j.1600-0706.2013.00829.x

May RM (1975). Patterns of species abundance and diversity. Ecology and Evolution of Communities 1975: 81-120.

McGill BJ, Etienne RS, Gray JS, Alonso D, Anderson $M J$, Benecha HK, Dornelas M, Enquist BJ, Green JL, He FL, Huilbert AH, Magurran AE, Marquet PA, Maurer BA, Ostling A, Soykan CU, Ugland KI, White EP (2007). Species abundance distributions: moving beyond single prediction theories to integration within an ecological framework. Ecology Letters 10: 995-1015. - doi: 10.1111/j.1461-0248.2007.01094.x

Motomura I (1932). On the statistical treatment of communities. Zoology Management 44: 379383.

Oksanen J, Blanchet FG, Friendly M, Kindt R, Legendre $P$, McGlinn D, Minchin PR, O'Hara RB, Simpson GL, Solymos P, Henry M, Stevens $H$, Szoecs E, Wagner H (2009). vegan: community ecology package. Version 1.15. R Project for Statistical Computing, Vienna, Austria. [online] URL: http://cran.r-project.org/web/packages/ve gan/index.html

Preston FW (1948). The commonness, and rarity, of species. Ecology 29: 254-283. - doi: 10.2307/19 30989

R Development Core Team (2016). R: a language and environment for statistical computing. $\mathrm{R}$ Foundation for Statistical Computing, Vienna, Austria. [online] URL: http://www.r-project.org Tan L, Fan C, Zhang C, Gadow KV, Fan X (2017). How beta diversity and the underlying causes vary with sampling scales in the Changbai mountain forests. Ecology and Evolution 7 (23): 10116-10123. - doi: 10.1002/ece3.3493

Tokeshi M (1993). Species abundance patterns and community structure. Advances in Ecological Research 24: 111-186. - doi: 10.1016/S00652504(08)60042-2

Tokeshi M (1990). Niche apportionment or random assortment: species abundance patterns 
revisited. Journal of Animal Ecology 59 (3): 1129-1146. - doi: 10.2307/5036

Walker SC, Cyr H (2007). Testing the standard neutral model of biodiversity in lake communities. Oikos 116: 143-155. - doi: 10.1111/j.2006.00301299.15300.x

Wang X, Hao Z, Ye J, Zhang J, Li B, Yao X (2008) Spatial pattern of diversity in an old-growth temperate forest in northeastern china. Acta Oecologica 33 (3): 0-354. - doi: 10.1016/j.actao. 2008.01.005
Williams CB (1964). Patterns in the balance of nature, and related problems in quantitative ecology. Academic Press, London, UK and New York, USA, pp. 324. [online] URL: http://www. cabdirect.org/cabdirect/abstract/19640603478 Wisz MS, Hijmans RJ, Li J, Peterson AT, Graham $\mathrm{CH}$, Guisan A, NCEAS Predicting Species Distributions Working Group (2008). Effects of sample size on the performance of species distribution models. Diversity and Distributions 14 (5): 763-773. - doi: 10.1111/j.1472-4642.2008.00482.x

\section{Supplementary Material}

Appendix 1 - Model description.

Appendix 2 - R script.

Tab. S1 - The abundance of each species in Changbaishan.

Tab. S2 - The abundance of each species in Jiaohe.

Tab. S3 - The abundance of each species in Liangshui.

Link:Tan_3211@supplo01.pdf 